\title{
STERNAL CLOSURE USING STEEL WIRES BY FIGURE OF EIGHT VERSUS INTERRUPTED SIMPLE SUTURES IN ADULT CARDIAC SURGERIES
}

\author{
Faisal Amr Mourad', Walaa Ahmed Saber Abd El Hameed ${ }^{1}$, Hossam El Din Ashour \\ Abd El Hameed ${ }^{1}$ and Mahmoud Mohamed Abu-Emma Mohamed ${ }^{2}$.
}

\begin{abstract}
${ }^{1}$ Cardiothoracic Surgery
Department Faculty of

Medicine Ain Shams

University ${ }^{2}$ Cardiothoracic

Surgery Department Mahalla

Cardiac Center.

*Corresponding Author:

Mahmoud Mohamed
\end{abstract}

Phone No.: (+2) 01090022406

E-mail:

Mo7taramgeddan@gmail.com

Received: $22 / 9 / 2020$

Accepted: 8/10/2020

Online ISSN: $2735-3540$

\begin{abstract}
Background: Median sternotomy is a commonly performed incision with distinct advantages in adult cardiac surgeries. The stainless-steel encircling wire used as either interrupted simple sutures or as figure of eight sutures is the current standard method of median sternotomy closure. Although sternotomy closure is straight forward, it is not without complications and if not recognized early can lead to complete sternal breakdown, sternal wound infection, and mediastinitis.
\end{abstract}

Aim of the Work: Comparison of the incidence of sternal stability, dehiscence and other sternal complications and the hospital stay.

Patients and Methods: One hundred consecutive patients who underwent sternal closure by steel wires in adult cardiac surgeries. Intervention: closure by steel wires using either; figure of eight sutures $n$ (50) group I or simple interrupted sutures $n$ (50) group II in adult cardiac surgeries in a specialized health care center between January 2018 till end of January 2019.

Results: Body mass index (BMI) as a risk factor between groups was statistically significant in relation to stability. $12 \%$ and $6 \%$ of patients with prolonged mechanical ventilation had sternal instability in group (I) and (II), respectively. 10 patients with prolonged ICU stay suffered sternal instability 9 were from group I andl was from group II (P value 0.022), so the techniques of closure should be considered whenever needed for prolonged ICU stay. Regarding the instability of sternum associated with prolonged post-operative hospital stay; it was found that $50 \%$ and $23.07 \%$ in group I and II which was statistically significant in relation to instability ( $P$ value 0.0382 ). The overall sternal dehiscence rate was 10\%; 8 cases in the in figure-of-8 sutures group and 2 in the simple interrupted sutures group. This was a statistically significant difference in rates of sternal dehiscence between the 2 groups ( $p$ 0.046).

Conclusion: It is concluded that simple interrupted suturing is more effective than figure-of-8 sternal suturing in preventing sternal dehiscence.

Keywords: Coronary artery bypass graft, Sternotomy, Wire closure, Open heart, Mediastinitis, Sternal Wound Infection

\section{INTRODUCTION:}

Median sternotomy is a commonly performed incision with distinct advantages for exposure of mediastinal and pulmonary hilar structures $^{(1)}$. 
Wiring, interlocking, plate-screw, and cementation techniques have been examined for sternotomy closure ${ }^{(2)}$.

The stainless-steel encircling wire used as either interrupted simple sutures or as figure of eight sutures is the current standard method of median sternotomy closure in cardiothoracic operations ${ }^{(3)}$.

A well-defined incidence of wound complications is associated with sternotomy, which are costly and potentially lethal in cases of deep sternal wound infection (DSWI) or mediastinitis ${ }^{(4)}$.

DSWI is a devastating postoperative complication that is associated with reduced mid and long-term survival compared with matched cardiac surgical patients ${ }^{(5)}$.

Although sternotomy closure is straight forward, it is not without complications. If not recognized early, instability of the bone fragments interferes with healing and can lead to complete sternal breakdown, sternal wound infection, and mediastinitis, which are major causes of morbidity and mortality after open- heart surgery ${ }^{(6)}$.

Other risk factors for sternal dehiscence include chronic obstructive pulmonary disease (COPD), redo surgery, renal failure, diabetes mellitus, chronic steroid use, obesity, concurrent infection and immunosuppression. Intraoperative risk factors such as off-midline sternotomy, osteoporosis, prolonged cardiopulmonary bypass, transverse fractures of the sternum, and bilateral internal mammary artery harvest have been identified ${ }^{(7)}$.

The ideal sternal closure should ensure stability, reduced rate of post-operative complications, and a short hospitalization period, alongside cost-effectiveness ${ }^{(2) .}$

\section{PATIENTS AND METHODS:}

Patients criteria; This prospective study comprised 100 randomly selected patients undergoing elective adult cardiac surgeries by surgical teams at Mahalla Cardiac Center, Egypt, between the period of January 2018 till end of January 2019. The patients were randomly divided into two equal groups:

- Group I: 50 patients with sternal closure figure of eight.

- Group II: 50 patients with sternal closure simple wire.

Pre-operative Preparations; The day before surgery, patients had antiseptic shower with diluted povidone-iodine and excessive hair in the chest wall was removed. Before skin incision, the patient's skin was disinfected with $10 \%$ povidoneiodine solution.

Antibiotic prophylaxis; All patients received prophylactic antibiotics prior to surgery ( $2 \mathrm{~g}$ of 3rd generation cephalosporin, e.g.: cefotaxime, 2 hours before surgery) and similar dose was given during the cardiopulmonary bypass. Additional postoperative doses were given during the ICU stay starting from the first day postoperative for $48 \mathrm{hrs}$.

Surgical Technique; All patients underwent elective cardiac surgeries via median sternotomy incisions and cardiopulmonary bypass.

The sternum was closed using stainless steel wires no "5" and delayed absorbable sutures were used for the subcutaneous tissues. The skin was closed with subcuticular absorbable sutures.

Group (I): Four twisted wires were always used to bridge the sternum in all patients with the following order of distribution:

1. One wire figure of 8 being included in the manubrium sterni.

2. One wire figure of 8 in manubriosternal junction. 
3. Two wire figures of 8 in the body of sternum.

All wires passed through the sternum 1 $\mathrm{cm}$ from the free edge of the sternal body. Initial hand twisting of all ends was done followed by vertical traction of each loop before the final twisting was done by the stainless-steel needle holder. Need to be mentioned that equalization of the wire distance in this technique is very significant in preventing wire dehiscence to equal distribute the tension forces on the sternum.

Group (II): All patients were closed by simple single sutures utilizing the No. 5 Stainless Steel Wire to make 10 stitches pass along the length of the sternum. In all patients, 4 simple wires were used for the manubrium. All wires passed through the sternum $1 \mathrm{~cm}$ from the free edge of the sternal body (trans sternal).

The end of each wire is then closed in the opposite side using horizontal traction to bring the sternal ends close to each other. Initial hand twisting of all ends was done followed by vertical traction of each loop before the final twisting was done by the stainless-steel needle holder. No more than 2 and half time twisting of the wire to prevent excessive traction and mechanical breakdown.

\section{Statistical analysis:}

The collected data was computed, tabulated, coded, verified and statistically analyzed with the aid of computer program SPSS statistical package version 17.0 on IBM compatible computer. Quantitative data was expressed as mean and standard deviation $(\mathrm{X} \pm \mathrm{SD})$, and qualitative data expressed as number and percentage (No. \& $\%$ ). Analysis was done by applying Pearson's Chi-Square test and Fisher's exact test. A P value of less than $0.05^{*}$ was considered statistically significant, a $\mathrm{P}>$ 0.05 (non-significant).

\section{RESULTS:}

In group (I) the mean cross clamp time (in minutes) was 67.22 with SD 13.071 while in group (II) the mean cross clamp time (in minutes) was 65.22 with SD 13.068. This difference was statistically insignificant ( $\mathrm{p}$ value 0.32 ).

Table (1): Intra-operative variables between groups:

\begin{tabular}{|c|c|c|c|c|c|}
\hline & & & & $\mathrm{t} / \mathrm{X} 2$ & $\mathrm{P}$ value \\
\hline \multirow{3}{*}{$\begin{array}{l}\text { Type of } \\
\text { surgery }\end{array}$} & Isolated CABG & $23(46 \%)$ & $24(48 \%)$ & \multirow[t]{3}{*}{0.223} & \multirow[t]{3}{*}{0.894} \\
\hline & Isolated valve & $23(46 \%)$ & $21(42 \%)$ & & \\
\hline & CABG/valve & $4(8 \%)$ & $5(10 \%)$ & & \\
\hline \multicolumn{2}{|c|}{ Mean bypass grafts (No.) } & $2.9 \pm 1.1$ & $2.7 \pm 1.1$ & 0.909 & 0.45 \\
\hline \multicolumn{2}{|c|}{ Operative time (hrs.) } & $5.6 \pm 1.4$ & $5.6 \pm 1.8$ & 0.310 & 0.98 \\
\hline \multicolumn{2}{|c|}{ Sternal closure time (min) } & $16.3 \pm 9.3$ & $18.9 \pm 9.0$ & 2.788 & $0.03 *$ \\
\hline \multicolumn{2}{|c|}{ Cross clamp time (min) } & $67.22 \pm 13.071$ & $65.22 \pm 13.068$ & 0.207 & 0.32 \\
\hline
\end{tabular}

* Sternal closure time: estimated time that begin with the first steel wire that pass through the first longitudinal half of sternum till the burial of the last wire knot's tip in the muscle. 


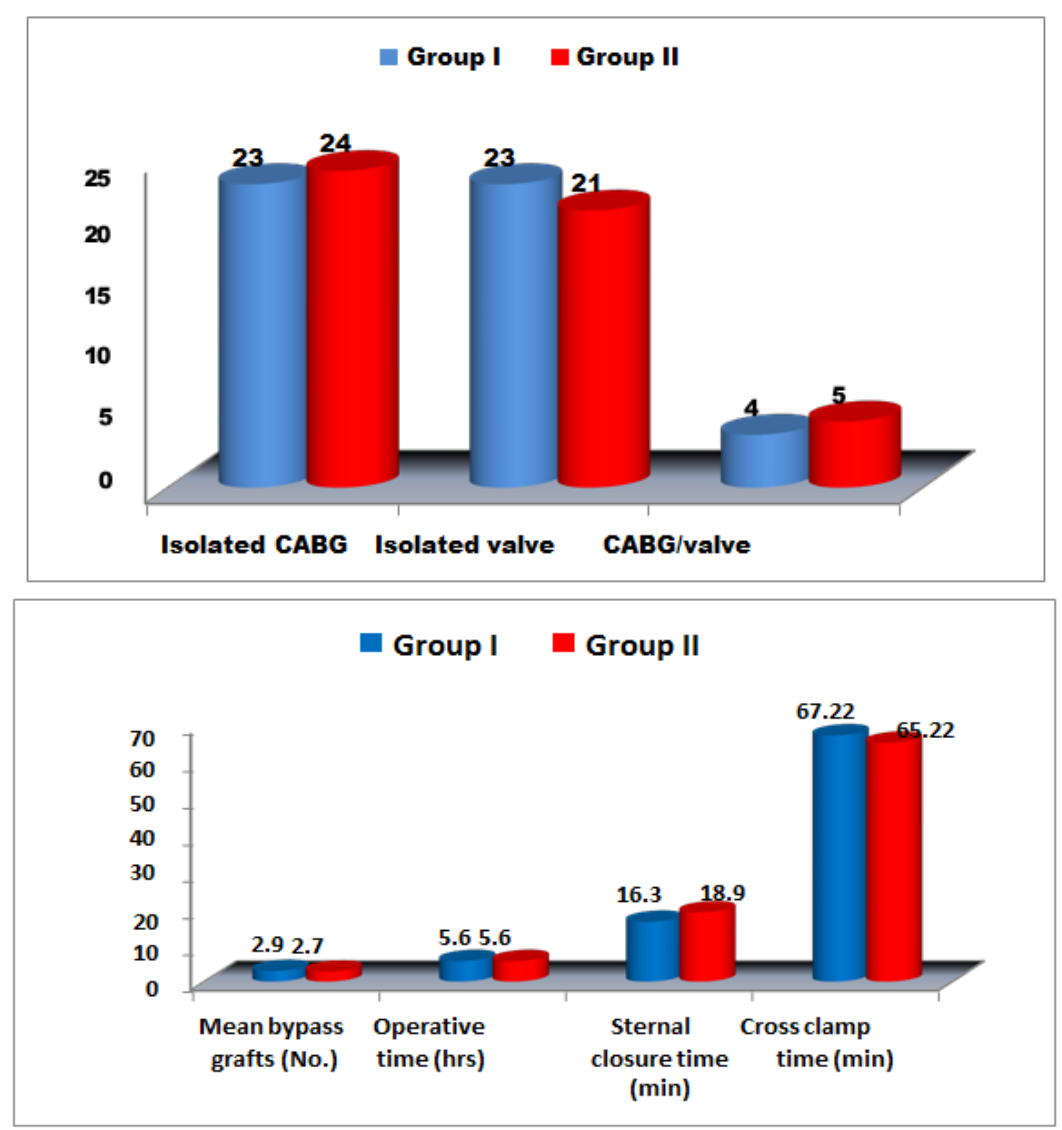

Figure (1): Intra-operative data.

Table (2): Variables of sternal instability:

\begin{tabular}{|c|c|c|c|c|c|}
\hline & & & & \\
\hline & & & & $\mathrm{t} / \mathrm{X} 2$ & $\mathrm{P}$ value \\
\hline \multicolumn{2}{|c|}{ AGE } & $53.48 \pm 6.3$ & $54 \pm 5.5$ & 0.440 & 0.661 \\
\hline \multirow[t]{2}{*}{ Sex } & $80 \%$ & $82.5 \%$ & $80 \%$ & \multirow[t]{2}{*}{0.065} & \multirow[t]{2}{*}{0.8} \\
\hline & $20 \%$ & $18 \%$ & $20 \%$ & & \\
\hline \multicolumn{2}{|c|}{ BMI } & $34.72 \pm 2.15$ & $35.68 \pm 2.10$ & 1.549 & $0.047 *$ \\
\hline \multicolumn{2}{|c|}{ E F } & $47.88 \pm 7.835$ & $50.88 \pm 7.536$ & 2.103 & $0.04 *$ \\
\hline \multicolumn{2}{|c|}{$\mathrm{DM}$} & $84 \%$ & $82 \%$ & 0.071 & 0.790 \\
\hline \multicolumn{2}{|c|}{ Cross Clamp time } & $67.22 \pm 13.071$ & $65.22 \pm 13.068$ & 0.207 & 0.32 \\
\hline \multicolumn{2}{|c|}{ Sternal dehiscence } & $\begin{array}{c}8 \\
16 \% \\
\end{array}$ & $\begin{array}{c}2 \\
4 \% \\
\end{array}$ & 4.000 & $0.046^{*}$ \\
\hline \multicolumn{2}{|c|}{$\begin{array}{l}\text { Duration of mechanical Ventilation } \\
10 \mathrm{~h} \text { and more and unstable sternum }\end{array}$} & $\begin{array}{c}6 \\
12 \%\end{array}$ & $\begin{array}{c}3 \\
6 \%\end{array}$ & 4.232 & $0.04 *$ \\
\hline \multicolumn{2}{|c|}{$\begin{array}{c}\text { I C U stay } \\
\text { more than } 2 \mathrm{~d} \text { and unstable sternum }\end{array}$} & $\begin{array}{c}9 \\
18 \%\end{array}$ & $\begin{array}{c}1 \\
2 \% \\
\end{array}$ & 2.41 & $0.022 *$ \\
\hline
\end{tabular}

Data are presented as mean \pm SD or Number of patients and \% to the group patients.

* Indicates a significant p value

\section{DISCUSSION:}

Median sternotomy approach is considered the golden classic exposure of the heart and the great vessels. Although closure of a sternotomy incision is usually a simple procedure, failure to do so (sternal dehiscence) is a serious complication that poses a high degree of morbidity or mortality after open heart surgery. The key 
factor in preventing sternal dehiscence is a stable sternal approximation until significant bone healing occurs; bony union depends on adequate reduction, fixation, and immobilization of the sternum. This relies on several factors: the technique of sternal closure, quality of the material used for sternal closure, and patient factors ${ }^{(8,9,10)}$.

We herein compare two techniques of sternal closure: The figure of eight (group I), versus the classic method using interrupted simple single sutures (group II).

In the study of Aykut $\mathrm{k}$ and colleagues $^{(8)}$, the mean age in years was $(59.4 \pm 9.4)$ in group $A$ and $(58.9 \pm 9.4)$ in group B (P 0.756) compared to $(53.4 \pm 6.3)$ and $(54.0 \pm 5.02)$ in our studied groups I and II, respectively (P 0.661). Female patients were $48 \%$ in group A and $52 \%$ in group B (p 0.372 ) compared to $20 \%$ and $18 \%$ in our studied groups I and II, respectively (p 0.8). Prolonged respiratory support was required in $(1.3 \%)$ and $(2.6 \%)$ in group $\mathrm{A}$ and $\mathrm{B}$ respectively (p 0.5$)$ compared to $(16 \%)$ and $(22 \%)$ in our studied groups I and II, respectively (p 0.444).

In our study Diabetes Miletus (DM) was found not that significant to the techniques of closure and this was similar to what (Ramzisham et al., 2009) ${ }^{(11)}$ found during his study in the 2 groups (P 0.790), so there was no strong correlation between sternum stability and DM, however there is strong relation between DM and mediastinitis as described by the overall mortality from cardiovascular disease is two to five times greater among diabetic patients than among non-diabetic patients.

Olbrecht et al. ${ }^{(7)}$, reported that the incidence of sternal dehiscence varies from $20 \%-25 \%$. We report a total incidence of $14 \%$ of our studied patient cohort at one month. Aykut k et al ${ }^{(8)}$ reported 8 cases of sternal dehiscence: 7 in group A and 1 in group B. The overall sternal dehiscence rates were $9.3 \%$ in group A and $1.3 \%$ in group B.
The difference was statistically significant ( $\mathrm{p}$ $<0.05$ ). In group A, 2 patients underwent reoperation because of sternal dehiscence with mediastinitis.

Similar to our results, the incidence of wound infection without sternal dehiscence was comparable in the studied groups by Aykut k et al. ${ }^{(8)}(p=0.316)$. Two $(2.6 \%)$ patients in their group A had mediastinitis with sternal dehiscence. In group B no patient had a diagnosis of mediastinitis. The difference between the 2 groups was not statistically significant $(\mathrm{p}=0.248)$.

Aykut k et al. ${ }^{(8)}$ concluded that simple interrupted sutures or figure-of-eight closure can be used for sternal closure in routine cases. It depends on the surgeon's preference and experience. However, prophylactic sternal weave closure (e.g. Robicsek) is more beneficial for diabetic obese patients. This technique reduces the incidence of sternal dehiscence, morbidity and mortality ${ }^{(8)}$.

The biomechanical behavior of the closure groups provides an important insight into the sternotomy separation. It suggests that the configuration and number of wires influences the closures' inherent stability or failure potential. Improved stability during the early healing stages is associated with more rigid sternal fixation, confirming our findings that a stable sternotomy is essential for complete and durable healing ${ }^{(9)}$.

With respect to stiffness the two closure methods that utilized single peri sternal Wires (namely, single peri sternal and combined peri sternal and transsternal) were not statistically different from one another and were both superior to all the other methods, perhaps because in both methods loops passed over the thick cortical layer, inhibiting wires from cutting through bone.

Lasnoff $^{(10)}$ study suggests that the exvivo human model using spiked clamps is valuable in comparing geometrically and mechanically varying closures using 
stainless steel wire. The model low cost and easy reproducibility make it a promising foundation for future sternotomy closure research. Subsequent studies using this model will utilize a larger number of specimens, closure methods, and statistical comparisons to clarify the role and technique of wire configuration in improved sternotomy closures.

In conclusion, the model of sternotomy closure testing described by Losanoff et $a l^{(10)}$ is reliable, cost-effective, and easily reproducible. The mechanical stability of peri sternal single wire closure is significantly greater than that of figure eight peri sternal and single transsternal closures. Peri costal figure- eight closures are not stable and should not be considered for primary sternotomy repair.

In our study we found that prolonged mechanical ventilation 10 hours and more in group (I), where figure of- 8 technique was adopted, was found to be statistically important (P 0.04). Six out of the 8 prolonged ventilated patients had unstable sternum. So, whenever there is high risk for prolonged mechanical ventilation we should go forward with interrupted simple wire for more stability, meanwhile Ramzisham et al. found that this risk factor was not significant between the two groups ${ }^{(11)}$.

In our study chest $\mathrm{x}$-ray has been proved to be an important significant finding in patients with sternal instability which was found similar to what Ramzisham et al (11) found and started to classify the sternal gap found in $\mathrm{x}$-ray to 3 groups.

Chest radiography can easily show a malposition wire or cut-through of the wire by the bone fracture ${ }^{(12)}$. In group (I) patients with chest $\mathrm{X}$ - ray positive finding including sternal gap $3 \mathrm{~mm}$ or more was found to be 6 $(60 \%$ within unstable sternum (n 10) and $12 \%$ within the group (n 50). In group (II) positive chest X-ray finding was observed in
1 patient (33\% within unstable sternum (n 3) and $2 \%$ within group (n 50). This difference was statistically significant in role of chest X-ray (with standard dose and magnification) in evaluating the degree of stability and the gap between the two sternal splits (P value 0.019). Ramzisham et al ${ }^{(11)}$ proposed the following classification for sternal dehiscence based on symptoms, signs, and radiological findings: type 1, asymptomatic with a mid-sternal strip $<3$ $\mathrm{mm}$; type 2 , mild to moderate sternal pain, rocking sternum, and a mid-sternal strip of 4-10mm with no infection; type 3 , severe pain, sunken sternum during breathing, midsternal strip 4-10 mm, and mediastinitis ${ }^{(11)}$.

The importance of this classification is in determining which patients can be treated conservatively. For type 1, conservative management may be advocated, and assessment by serial chest radiographs is important to determine whether the dehiscence has resolved. For types 2 and 3, surgical intervention is imperative at the time of diagnosis to reduce the rates of morbidity and mortality.

We found that retrosternal collection proven by CT- chest can be used as an early predicator for sternum instability between the 2 groups ( $\mathrm{P}$ value 0.027 ), as most of our patients who developed instability in the form of sterile rocking had positive CT finding with retrosternal collection.

The duration of hospital stay postoperative is one of the most important factors in dealing with patients with sternum instability. They represent a burden to the resources of the hospital regarding the cost of management and the budget needed for a 2nd reconstructive surgery if needed.

Regarding the post-operative hospital length stay, our study showed that in group I, $50 \%$ of unstable sternum patients had a hospital stay of more than 10 days while in group II, $23.07 \%$ had a hospital stay of more than 10 days ( $\mathrm{p} 0.0382$ ). 
In our study, we didn't find any strong statistical significance between the incidences of sternal dehiscence and superficial wound infections $(\mathrm{P}>0.05)$. In group (I) there were 3 patients $(6 \%)$ presented with superficial wound infection (SWI), while in group (II) there were 2 patients with superficial wound infection (4\%) (P value 0.646). This was statistically insignificant. Even though among the patients with SWI in group (I) all of the three patients with SWI had sternal dehiscence in the form of rocking which adopt the relation between infection and sternal dehiscence, while in group (II) one patient preceded to sternum dehiscence. In other studies, incidence of sternal dehiscence without infection of $6.5 \%$, and with infection of $1.5 \%$, is comparable to results of several studies showing sternal dehiscence with mediastinitis in $1 \%-5 \%$ of cases. Sternal dehiscence is associated with significant morbidity and mortality rates of $14 \%$ $50 \%{ }^{(13)}$.

Matching the results of Fahad M. et al (14), in our group (I) there were 2 cases of deep sternal wound infection, while in group (II) there were no reported cases of deep sternal wound infection. This was statistically insignificant $(\mathrm{P}>0.05)$. Had to be mentioned that the 2 cases in group (I) suffered from deep wound infection, had poor outcomes even after good debridement, applying VAC therapy for infection control and good drainage, the 2 cases was re-entered for 2nd surgery pectoralis major flap, one case died after pectoral flap by 1 week in ICU and the other case died at home after being discharged from 2 nd surgery after 3 month.

From our results, we found that morbid obese, prolonged mechanical ventilation; ICU and postoperative hospital stay can be identified as a risk factor for sternum instability and the simple wire technique decrease the incidence of instability and should be adopted as first line for sternotomy closure.

One of this study limitations is that it needs to be implied on a bigger scale of population and to be compared with other studies. Further studies using Meta-analysis can help this kind of study and trails to expand the target group and isolate each variable alone to be studied meticulous and define more variables and risk factors.

\section{Conclusion:}

Despite its near universal use for cardiac and great vessels exposure, sternal split remains today a significant risk factor with an incidence of dehiscence and infection ranging from 1 to $5 \%$ in different reports.

The periosteal devitalization by the surgical maneuver together with the frequently prolonged exposure both put the sternal edges at jeopardy for proper healing. A strict midline sternotomy, minimal use of bone wax and diathermy, and skeletonized dissection or a narrow pedicled internal mammary are all useful to limit damage to the vascularity of the sternum.

The most important factor in preventing sternal wound complications is a stable sternal approximation; as bony union depends on adequate reduction and immobilization of the sternocostal junctions.

Various innovative techniques have been described to achieve maximum sternal stability and each technique has its own advantages and disadvantages. The use of our sternal closure significantly decreases the need for more complicated rescue techniques for failed routine closures. Despite the simplicity of this technique, we believe that its closure strength rivals that of more complex wiring procedures. Preoperative (e.g., advanced age, obesity, chronic obstructive pulmonary disease), intraoperative (e.g., low cardiac output, inaccurate sternal division, prolonged cardiopulmonary bypass), and postoperative (e.g., prolonged ventilatory support, 
malnutrition, external cardiac compressions) risk factors can impair sternal stability.

\section{REFERENCES:}

1. Dürrleman, n. \& massard, g. J. M. M. O. C. S. M. 2006. Posterolateral thoracotomy. 2006, mmcts. 2005.001453-mmcts. 2005. 001453.

2. Alhalawani, a. M. \& towler, m. R. J. J. O. B. A. 2013. A review of sternal closure techniques. 28, 483-497.

3. Goodman, g., palatianos, g. \& bolooki, h. J. T. J. O. C. S. 1986. Technique of closure of median sternotomy with trans-sternal figure-of-eight wires. 27, 512-513.

4. Hollenbeak, c. S., murphy, d. M., koenig, s., woodward, r. S., dunagan, w. C. \& fraser, v. J. J. C. 2000. The clinical and economic impact of deep chest surgical site infections following coronary artery bypass graft surgery. 118, 397-402.

5. Kotnis-Gąska, A., Mazur, P., OlechowskaJarząb, A., Stanisz, A., Bulanda, M. \& Undas, A. J. K. I. T. P. P. J. O. C. T. S. 2018. Sternal wound infections following cardiac surgery and their management: a single-centre study from the years 20162017. 15, 79.

6. Dell'Amore, A., Campisi, A., GiuntA, D., Congiu, S., Dolci, G., MuranA, G., Suarez, S. M. \& Daddi, N. J. J. O. T. D. 2018. Surgical options to treat massive sternal defect after failed Robicsek procedure. 10, E410.

7. Olbrecht, V. A., Barreiro, C. J., Bonde, P. N., Williams, J. A., Baumgartner, W. A., GOTT, V. L. \& Conte, J. V. J. T. A. O. T. S. 2006. Clinical outcomes of noninfectious sternal dehiscence after median sternotomy. 82, 902-907.
8. Aykut, K., Celik, B. \& Acikel, U. J. T. A. O. T. S. 2011. Figure-of-eight versus prophylactic sternal weave closure of median sternotomy in diabetic obese patients undergoing coronary artery bypass grafting. 92, 638-641.

9. Sargent, L. A., Seyfer, A. E., Hollinger, J., Hinson, R. M. \& Graeber, G. M. J. T. A. O. T. S. 1991. The healing sternum: A comparison of osseous healing with wire versus rigid fixation. 52, 490-494.

10. Losanoff, J. E., Collier, A. D., Wagner Mann, C. C., Richman, B. W., Huff, H., Hsieh, F.-H., Diaz-Arias, A. \& Jones, J. W. J. T. A. O. T. S. 2004. Biomechanical comparison of median sternotomy closures. 77, 203-209.

11. Ramzisham, A.-R. M., Raflis, A. R., Khairulasri, M. G., Min, J. O. S., Fikri, A. M., Zamrin, M. D. J. A. C. \& Annals, T. 2009. Figure-of-eight vs. interrupted sternal wire closure of median sternotomy. 17, 587-591.

12. Peivandi, A., Vogel, N., Opfermann, U., Singelmann, J., Kuroczynski, W., Kreitner, K., Dahm, M., Vahl, C. J. T. T. \& Surgeon, C. 2006. Early Detection of Sternal Dehiscence by Conventional Chest X - Ray. 54, 108-111.

13. El, R. O., Paul, E., Wong, P., YOHANA, A., Magee, P., Walesby, R. \& Wright, J. J. T. J. O. C. S. 1997. Mediastinitis in patients undergoing cardiopulmonary bypass: risk analysis and midterm results. 38, 595-600.

14. Fahad M. Al Majid, Faruk Buba, Mazen Barry, Fatima Alsharani, Fawzan Alfawzan 2020. Incidence, types and outcomes of sternal wound infections after cardiac surgery in Saudi Arabia. A retrospective medical chart review. Saudi Med J 2020; 41: 177-182. doi: 10.15537/smj. 2020. 2. 24843 
غلق عظمة القص باستخدام الأسلاك الفولاذية بأسلوب الثكل ثمانية (^) مقارنة بأسلوب الغرز البسيطة المتقطعة في الجراحات القلبية للبالغين

فيصل عمرو مراد، ولاء أحمد صابر عبد الحميد، حسام الدين عاثور عبد الحميد،

محمود محمد أبو عمه محمد الحمدام

الخلقية: يعد الثق المنصف لعظمة القص هو واحد من الأساليب المتعددة التي يمكن استعمالها في الجراحات القلبية للبالغين.

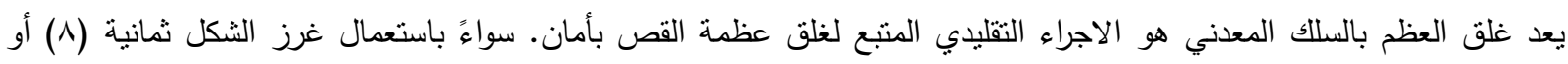
الغرز البسيطة المتقطعة.

الههف: تهدف هذه الدراسة الى الدقارنة بين أسلوبين واسعي الاستخدام وهو أسلوب الغرز البسيطة المتقطعة وأسلوب غرز

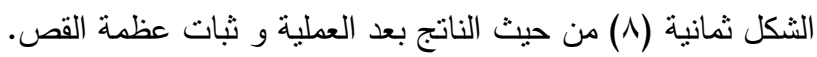

المرضى والطرق: لقد قمنا بعمل هذه الدراسة الاستشرافية علي مجموعة عشوائية من المرضي لنقارن معدل حدوث المضاعفات

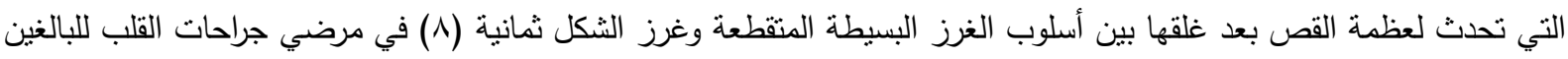

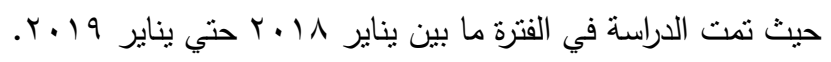

النتائج: قد كان لهذا استخلال احصائي فارق في معدل حدوث التهناك بين المجموعتين. وهذا ان دل فانه يدل على أن الغلق بأسلوب الغرز البسيطة المتقطعة أكثر فاعليه من الغلق بأسلوب غرز الثكل ثمانية في منع حدوث تهنانك عظمة القص. الاستتاج: نستتنج أن أسلوب الغرز البسيطة المنقطعة أكثر فاعلية من أسلوب غرز الثكل ثمانية (^) في منع تهنك عظمة 